COMUNICAÇÃO CIENTÍFICA

\title{
DISTRIBUIÇÃO GEOPOLÍTICA DA FASCIOLOSE HEPÁTICA NA ILHA DE SANTIAGO, CABO VERDE
}

\section{L.M.M. de Matos ${ }^{1}$, E.A. Pile ${ }^{2}$, C.H.B.A. Almada ${ }^{1}$, H.S.C. Lima ${ }^{1}$, S.M.M. Ahid ${ }^{3}$}

${ }^{1}$ Instituto Nacional de Investigação e Desenvolvimento, São Jorge dos Órgãos, llha de Santiago, 84, Cabo Verde. E-mail edwinpile@hotmail.com

\section{RESUMO}

\begin{abstract}
O trabalho foi realizado no intuito de registrar a distribuição geopolítica da Fasciolose Hepática na Ilha de Santiago, Cabo Verde. Durante a avaliação, realizada de maio a junho de 2008, foram registrados tamanho e taxas de infecção do molusco, $\mathrm{pH}$ e temperatura da água e taxas de infecção de vertebrados. As amostras de moluscos e de fezes de bovinos foram coletadas, de forma aleatória, em todos os municípios da Ilha de Santiago, com exceção de Tarrafal, e, devidamente embaladas, encaminhadas para o Laboratório do Instituto Nacional de Investigação e Desenvolvimento Agrário (INIDA), onde foram analisadas. As análises demonstraram resultados positivos para a coproscopia de bovinos e a presença do hospedeiro intermediário (Lymnaea natalensis) em todos os municípios visitados. Também ficou demonstrada uma correlação positiva entre a taxa de infecção dos hospedeiros vertebrados e invertebrados, sendo que o maior índice foi registrado no Município de Santa Cruz (72,72\%) e o menor no da Praia $(16,66 \%)$. A taxa de infecção média verificada para os moluscos e os bovinos foi de $51,51 \%$ e $37,15 \%$, respectivamente.
\end{abstract}

PALAVRAS-CHAVE: Fasciola sp., Fasciolose, Cabo Verde.

\section{ABSTRACT}

GEOPOLITIC DISTRIBUITION OF HEPATICFASCIOLOSISONSANTIAGOISLAND, CAPE VERDE. A survey was carried out in order to study the geopolitical distribution of fascioliasis on Santiago Island, Cape Verde. During the evaluation, conducted from May to June 2008, measurements were made and recorded regarding the size and infection rates of the snail, $\mathrm{pH}$ and water temperature and vertebrate infection rates. Snails and bovine feces samples were collected at random in all municipalities of Santiago Island, except Tarrafal, properly packed, and sent to the Laboratory of National Institute of Agricultural Research and Development (INIDA) where they were analyzed. The results showed positive results for stool examinations of cattle and the presence of an intermediate host (Lymnaea natalensis) in all localities visited. A positive correlation was also found between the vertebrate and invertebrate infection rate, with the highest rate recorded in Santa Cruz (72.72\%) and the lowest in Praia (16.66\%). The average infection rate observed for the snails and cattle was $51.51 \%$ and $37.15 \%$, respectively.

KEY WORDS: Fasciola sp, Fasciolose, Cape Verde.

Cabo Verde está situado entre o Equador e o Trópico de Câncer, entre os paralelos $17^{\circ} 12^{\prime}$ e $14^{\circ} 48^{\prime}$ de latitude norte e os meridianos $22^{\circ} 44^{\prime}$ e $25^{\circ} 22^{\prime}$ de longitude oeste. É um país constituído por dez ilhas (Santo Antão, São Vicente, Santa Luzia, São Nicolau, Sal, Boavista, Maio, Santiago, Fogo e Brava) e treze ilhéus, localizado a cerca de $450 \mathrm{~km}$ da costa ocidental africana, ao largo do Senegal. De origem vulcânica, as ilhas mostram em geral topografias muito acidentadas, com vales de vertentes abruptas, profundos e ramificados. Ocupam, no seu conjunto, uma superfície emersa total de $4.033 \mathrm{~km}$ e uma Zona Econômica
Exclusiva (ZEE) que se estende por cerca de 734.000 $\mathrm{km}$. Pela sua posição, Cabo Verde está sujeito ora às influências climáticas da faixa de baixas pressões equatoriais, responsável pela chuva no país (julho a outubro), ora às altas pressões subtropicais, de onde sopram os ventos alísios de NE (novembro a junho). Oclima é de tipo quente, tropical seco, com chuvas irregulares, que podem ser demasiadoescassas durante longos períodos de tempo. A vegetação naturalérara, em especial nas regiões baixas e áridas, mas, durante o período das chuvas, o ambiente altera-se completamente com o aparecimento de plantas herbáceas

${ }^{2}$ Universidade de Cabo de Cabo Verde, Departamento de Ciências e Tecnologia, Santiago, Palmarejo, Cabo Verde.

${ }^{3}$ Universidade Federal Rural do Semiárido, Departamento de Ciências Animais, Mossoró, RN, Brasil. 
que cobrem as zonas de altitude, enquadrando-se no arquipélago da Macaronésia. O relevo é geralmente muito acidentado, culminando com altitudes muito elevadas (Fogo - 2.829 m, Santo Antão - 1.979 m, Santiago - 1.395 m, São Nicolau - 1.340 m) (SIA, 2009). Santiago faz parte do grupo de ilhas de sotavento do arquipélago de Cabo Verde. Possui uma superfície de 991 km, sendo a maior ilha de Cabo Verde. Apresenta um alongamento no sentido SE-NW, de cerca de $55 \mathrm{~km}$, e uma largura estimada em $37 \mathrm{~km}$. Da sua morfologia evidenciam-se as achadas (superfícies de feição planáltica), as encostas ou vertentes, os vales das ribeiras, os maciços montanhosos e as colinas (DINIS; MAtos, 1986; SIA, 2009). A distribuição geopolítica atual, verificada na Figura 1, não é mesma que a registrada no período da realização do trabalho (Tabela 1). Entretanto, os novos municípios estão inseridos nos locais onde foram registradas as maiores taxas de infecção, tanto para os hospedeiros vertebrados quanto invertebrados. Os bovinos explorados não têm um padrão racial definido, entretanto, nos últimos anos houve entrada, embora não significativa, de animais com padrões apurados para a aptidão leiteira, provenientes das Ilhas Canárias. Em 2004, o rebanho bovino da ilha alcançava as 15.206 cabeças (INSTITUTO..., 2004). A maior parte destes animais é criada em pequenos currais ao redor das casas, devido às dificuldades de obtenção de recursos forrageiros e água.

Cabo Verde é um país que ainda se encontra no seu processo de transição epidemiológica, caracterizado pela prevalência, em simultâneo, de doenças típicas de países desenvolvidos (sobretudo as doenças crônico-degenerativas) e daqueles menos desenvolvidos, como são os problemas infecciosos e parasitários. Ainda, enfrenta dificuldades originadas por deficiências na infraestrutura de saneamento básico, por comportamentos, atitudes e práticas das populações que demonstram carências na informação e educação voltadas para a defesa do ambiente e para a promoção e proteção da saúde. Este quadro tem contribuído para que o país, ainda, mantenha uma vulnerabilidade importante, no relacionado a muitas doenças de origem ambiental e com potencial epidêmico (CABO Cerde, 2004). Considerando estes aspectos decidiu-se pela verificação da distribuição da Fasciolose Hepática, doença que, no país, é provocada por Fasciola gigantica, sendo seu hospedeiro intermediário Lymnaea natalensis. Esta doença é um problema de alta morbilidade que representa sérios prejuízos econômicos para a criação de bovinos, caprinos e ovinos, destacando-se ainda que também é capaz de afetar o homem, fato já corroborado na ilha (Cruz-Silva, 1974; Pile et al., 2008; Pile; Semedo, 2006; Rosa et al., 1999). No entanto, as citações se encontram restritas somente a alguns dos municípios (Rosa et al., 1999). Na realização do trabalho foram abordados todos os munícipios da ilha, com exceção de Tarrafal, zona norte da ilha (Fig. 1), no período de Maio a Junho de 2008. Durante as visitas foram coletados moluscos e amostras de fezes de bovinos. Este material, devidamente embalado era remetido ao Laboratório do Instituto Nacional de Investigação e Desenvolvimento Agrário (INIDA), onde era processado de acordo com a sua natureza (os moluscos eram mensurados com auxílio de paquímetro e as amostras de fezes de bovinos eram processadas através de técnicas coproparasitológicas de sedimentação). A temperatura e o $\mathrm{pH}$ da água também foram registrados durante as visitas. Durante o recorrido foram visitados 19 locais em oito dos nove municípios. Em todas as zonas se procurou por locais com pequenos açudes, córregos e áreas de plantação de hortaliças [Presença de agrião (Nasturtium officinale)]. Os resultados demonstraram coproscopia positiva para as amostras de bovinos e a presença do molusco em todos os municípios visitados. Para os moluscos $(n=1.620)$ foi registrado um tamanho médio de 9,38mm e taxa de infecção de $51,51 \%$. Já nos bovinos $(\mathrm{n}=118)$ foi registrada uma taxa de infecção de 37,15\% (Tabela 1).

Tabela 1 - Análise descritiva dos fatores avaliados durante levantamento da fasciolose hepática na Ilha de Santiago, no período de maio a junho de 2008.

\begin{tabular}{|c|c|c|c|c|c|c|c|c|c|}
\hline & \multicolumn{4}{|c|}{ Moluscos } & \multicolumn{2}{|c|}{ Vertebrados } & \multicolumn{3}{|c|}{ Água } \\
\hline & biótopos & $\mathrm{n}$ & tamanho $(\mathrm{mm})$ & infecção (\%) & $\mathrm{n}$ & infecção (\%) & $\mathrm{n}$ & $\mathrm{pH}$ & temperatura $\mathrm{C}$ \\
\hline Praia & 1 & 1 & 9.00 & 0,00 & 10 & 16.66 & 3 & 7.00 & 23.00 \\
\hline Ribeira Grande & 4 & 113 & $8,23 \pm 1,56$ & $60 \pm 0,00$ & 18 & $67.36 \pm 7.90$ & 12 & $7.34 \pm 0.74$ & $24.90 \pm 1.03$ \\
\hline Santa Catarina & 3 & 428 & $9.68 \pm 1.78$ & $49.28 \pm 10.48$ & 10 & $30.86 \pm 20.94$ & 9 & $7.19 \pm 0.29$ & $22.39 \pm 6.59$ \\
\hline Santa Cruz & 1 & 85 & $12.00 \pm 2.25$ & 80.00 & 10 & 72.72 & 3 & 6.80 & 25.00 \\
\hline São Domingos & 1 & 83 & $9.17 \pm 1.14$ & 40.00 & 10 & 57.14 & 3 & 8.00 & 21.00 \\
\hline São Lourenço dos Órgãos & 1 & 71 & $6.24 \pm 1.78$ & 70.00 & 10 & 42.86 & 3 & 7.00 & 23.50 \\
\hline São Miguel & 3 & 615 & $9.70 \pm 2.49$ & $52.07 \pm 24.95$ & 10 & 29.45 & 9 & $7.70 \pm 0.96$ & $26.08 \pm 1.94$ \\
\hline São Salvador do Mundo & 5 & 224 & $8.60 \pm 3.26$ & $37.64 \pm 9.96$ & 40 & $25.00 \pm 0.00$ & 15 & $6.85 \pm 0.45$ & $19.38 \pm 3.92$ \\
\hline Total & 19 & 1620 & $9,38 \pm 2.51$ & $51,51 \pm 19,41$ & 118 & $37,15 \pm 25,37$ & 57 & $7,36 \pm 0,75$ & $23,66 \pm 4,56$ \\
\hline
\end{tabular}

Valores significativamente inferiores à média.

Valores significativamente superiores à média.

Teste $\mathrm{t} ; \mathrm{p}<0,05$. 


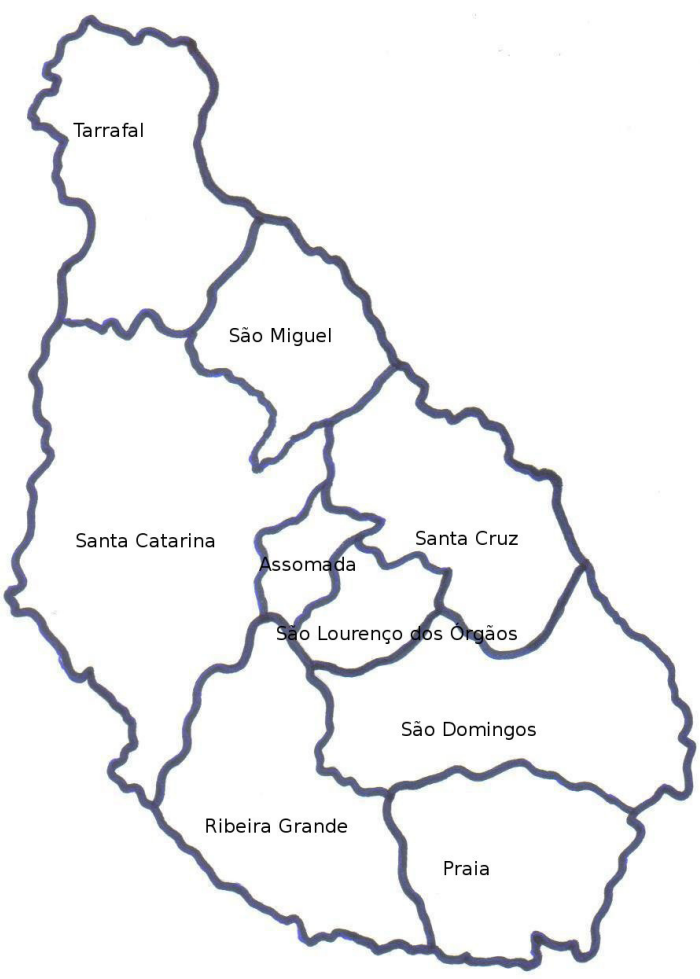

Fig. 1 - Representação gráfica da Ilha de Santiago.

Registra-se ainda que as maiores taxas de infecção entre os bovinos se encontravam nos municípios de Ribeira Grande e Santa Cruz e as menores nos de Praia e São Salvador do Mundo (ANOVA, p < 0,05), indicando-se, além desta correlação, uma correlação com o $\mathrm{pH}$ da água $(\mathrm{r}=0,27$; $\mathrm{p}<0,05)$ (Tabela 1).

\section{REFERÊNCIAS}

CABO VERDE. Ministério do Ambiente, Agricultura e Pesca. Livro branco sobre o estado do ambiente em Cabo Verde. Cabo Verde: MAAP, Direcção Geral do Ambiente, 2004. 228p. (Technical Report).

CRUZ-SILVA, J. Estudos de parasitologia em Cabo Verde. Garcia de Orta. Série Zoologia, v.3, n.1, p.2134, 1974.

DINIZ, A.C.; MATOS, G.C. Carta de zonagem agroecológica e da vegetação de Cabo Verde - ilha de Santiago. Lisboa: Garcia de Orta, 1986. (Série de Botánica).

\section{INSTITUTO NACIONAL DE ESTATISTICA (CABO} VERDE). Censo: recenseamento geral da agricultura. Cabo Verde: INE, 2004. (Technical Report).

PILE, E.; SEMEDO, C. Fascioliasis prevalence in Cape Verde. Revista de Estudos Cabo-verdianos, v.1, n.3/4, p.121-122, 2006.

PILE, E.; AHID, S.; SILVA, D. Variação mensal da fasciolíase entre pacientes com distúrbios gastro-hepáticos em Santiago, Cabo Verde. Biológico, São Paulo, v.70, n.1, p.1518, 2008.

ROSA, F.; SIMÕES, M.; COSTE, F. Distribuição geográfica dos moluscos dulçaquícolas na ilha de Santiago (Cabo Verde). Garcia de Orta. Série Zoologia, v.23, n.1, p.193, 1999.

SIA - Sistema de Informação Ambiental (Cabo Verde). Caracterização geográfica de Cabo Verde. 2009. Disponível em: <http://www.sia.cv/>. Acesso em: jun. 2011.

Recebido em 22/6/09

Aceito em 5/1/11 